\title{
HEAD SHAKING WITH NYSTAGMUS IN INFANTS
}

\author{
A STUDY OF SIXTY-FOUR CASES * \\ CHARLES HERRMAN, M.D. \\ NEW YORK
}

Nomenclature.-Various names have been given to this condition. Those which include the word spasm, such as spasmus nutans, nutatio capitis spastica, gyrospasm, nodding spasm, are objectionable, because it is not a spasm in the sense in which that term is usually used. The terms gyrospasm, rotatory spasm, head nodding and nodding spasm are inaccurate, because the movements may be in any direction. The term spasmus nutans has sometimes led to confusion with the condition known as eclampsia or epilepsia nutans, which is an entirely different disease. Salaam tic, a term sometimes used by French authors, is objectionable because this condition has none of the characteristic features of a tic. Everything considered, head shaking with nystagmus, seems to be the least objectionable name.

Historical.-This condition was first described by Ebert ${ }^{1}$ in 1850 , and in 1851 by Romberg and Henoch. ${ }^{2}$ In 1890 Hadden $^{3}$ published two important papers, with a report of twenty-one cases. Caillé ${ }^{4}$ of New York was the first to note that when the nystagmatic eye or eyes were bandaged, the movements of the head ceased. In 1897 Raudnitz $^{5}$ published his exhaustive monograph on the subject, based on fifteen cases, in which he particularly emphasized the importance of the dark room in the etiology of this condition. In 1911 he published a report on the production of this condition experimentally in young dogs. In England and Scotland, Still ${ }^{6}$ and Thomson ${ }^{\top}$ have reported large series of cases. In this country Peterson, ${ }^{8}$ Aldrich, ${ }^{9}$ Abt, ${ }^{10}$ Judson, ${ }^{11}$ Miller, ${ }^{12}$ Hamill and Posey, ${ }^{13}$ Hill ${ }^{14}$ and others have published cases.

* Submitted for publication May 29, 1918.

* Read at the Annual Meeting of the American Pediatric Society, Lenox, Mass., May, 1918.

1. Ebert: Charité-Ann., 1850, 1, 752.

2. Henoch and Romberg: Klin. Wahrnehm. u. Beobact., Berlin, 1851.

3. Hadden: Lancet, London, 1890, 1, 1293; St. Thomas Hosp. Rep., 1890, 20, 205.

4. Caillé: Arch. Pediat., 1890, 7, 171.

5. Raudnitz: Jahrb. f. Kinderh., 1897, 45, 144; Jahrb. f. Kinderh., 1911, 73, 259.

6. Still: Lancet, London, 1906, 2, 207; Clin. Jour, 1906, 29, 90.

7. Thomson: Jacobi Festschrift, 1900; Brit. Med. Jour., 1901, 1, 763.

8. Peterson: New York Med. News, 1892, 61, 374.

9. Aldrich: Am. Jour. Med. Sc., 1899, 177, 158.

10. Abt: Jour. Am. Med. Assn., 1900, 34, 269.

11. Judson: Arch. Pediat., 1899, 16, 197.

12. Miller: Arch. Pediat., 1900, 17, 561.

13. Hamill and Posey: Am. Jour. Med. Sc., 1904, 128, 875.

14. Hill: Arch. Pediat., 1911, 28, 974. 
Frequency.-This condition seems to be more common in some countries than in others, if we may judge by the number of reported cases. It is certainly more frequent in large cities. In Budapest at the children's clinic, 15 cases were observed in 3 years among 52,215 patients; in Prague, 8 cases in 2 years among 1,223 patients; in Edinburgh, 35 cases in 11 years among 21,752 patients; in Basel, 2 cases among 6,154 patients; in Christiania 10 cases were seen at the children's clinic in 10 years. The disease appears to be not uncommon in London, Edinburgh, Berlin; and in this country in New York and Philadelphia. During the last 19 years I have had 64 cases under my observation at various children's clinics in New York. The first 15 were seen during 1899, 1900, 1901, at the Good Samaritan Dispensary, chiefly in the service of Dr. Koplik. These figures would indicate that this condition is met with in New York City in about 1 in every 700 infants coming for treatment. The number of cases varies markedly in different years: In 1901 I saw 8 cases; in 1906, 9 cases; in 1910, 13 cases, and in 1918, 7 cases ; whereas in some years, $1904,1908,1909,1912,1914,1916$, no cases were seen. This difference in the prevalence of the disease in different years has also occurred in other cities; for example, in Budapest, in 1891, there was one case in 17,400 patients; in 1894,9 cases in 16,563 patients. It is relatively somewhat more common among negro children than among white children in New York. In $1910 \mathrm{I}$ saw 10 cases in negro children at the Vanderbilt Clinic. This is probably due to the poor hygienic conditions and the greater prevalence of marked rickets in these children.

Sex.-Females are slightly more frequently affected. In my series, there were 29 males, 35 females. In 133 previously reported cases there were 62 males, and 71 females.

Seasonal incidence.-This condition shows a very distinct seasonal incidence, as shown in the accompanying tabulation.

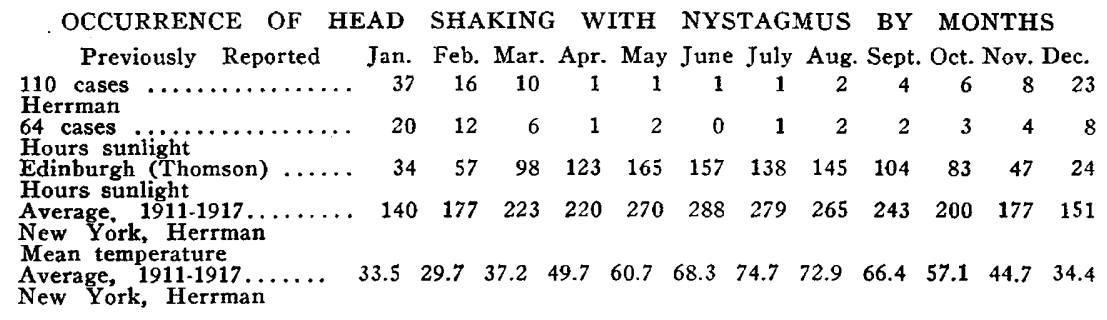

It will be seen, Figure 1, that it is much more prevalent during the winter months, nearly 70 per cent. of all cases occurring during December, January, and February. The largest number of these begin in January, and recurrences are almost always in this month. As 
Thomson has pointed out, the number of hours of sunlight, in temperate climates, is at its minimum during the winter months, Figure 2, and this may hear a definite relation to the prevalence of the condition. It may also account for the very few cases reported in France, Italy, and Spain, for it seems very unlikely that the disease could be overlooked. However, it does not appear probable that the relation is a direct one, and there is no reason to suppose that the amount of sunlight bears a direct relation to this disease. It would be interesting to determine whether head shaking is rare in countries in which there is an unusually large percentage of sunshiny days, for example, New

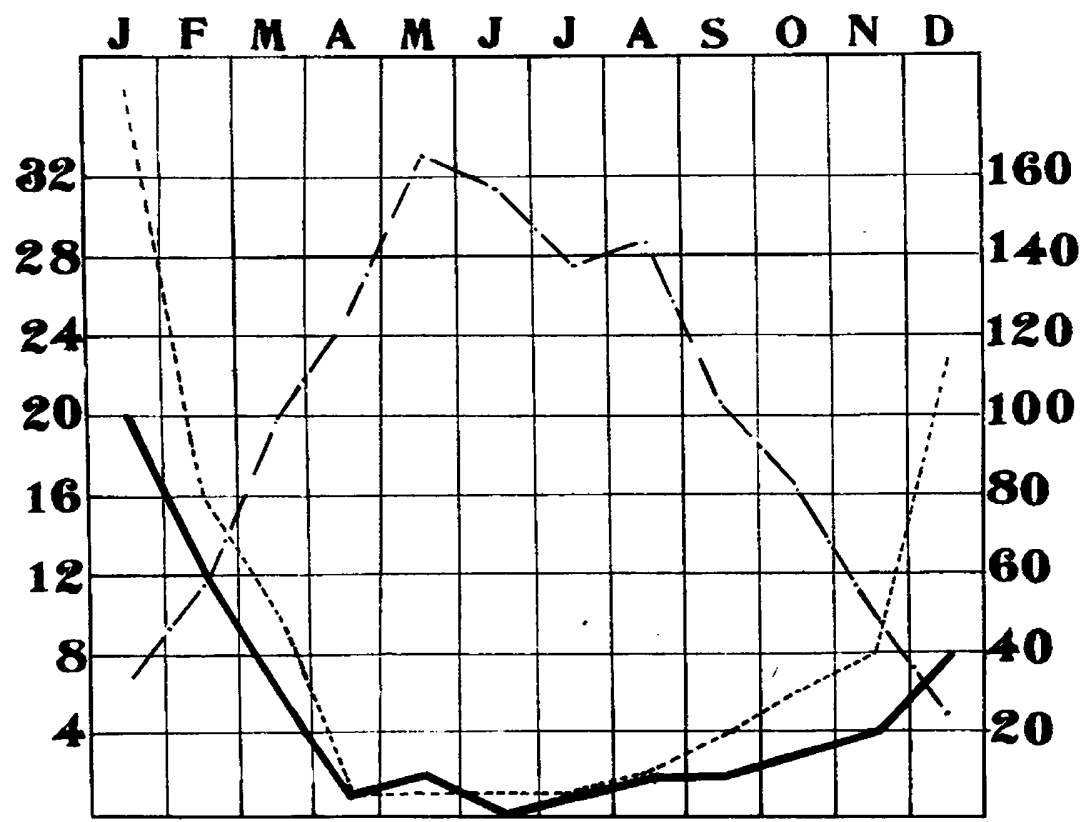

Fig. 1.-Seasonal incidence of head shaking with nystagmus; sixty-four cases observed by the author; $-\ldots-\ldots-110$ previously reported; -...-. number of hours of sunlight each month in Edinburgh (Thomson).

Zealand, and whether the condition is prevalent in the months of December, January, and February in places in which the summer and winter seasons are different than our own. It will be noted, Figure 2, that the incidence curve of head shaking also corresponds quite closely to the mean temperature curve, so that the temperature might also be important, in so far as during very cold weather the windows would be closed and the infants would not be taken out as much as usual. This may possibly account for the unusually large number of cases seen during the past winter, which was an extremely severe one. 
Age incidence.-The disease is most common between 4 and 12 months of age, 75 per cent. of all cases occurring at that time. In my series the age of onset could be definitely determined in 61 . It was 1 at 1 month, 2 at 2 months, 2 at 3 months, 2 at 4 months, 3 at 5 months, 8 at 6 months, 8 at 7 months, 5 at 8 months, 5 at 9 months, 6 at 10 months, 4 at 11 months, 6 at 12 months, 2 at 13 months, 3 at 15 months, 1 at 20 months, 2 at 21 months, and 1 at 4 years. The youngest in the series was 1 month old. Schoenberg ${ }^{15}$ has also reported a case at that age, and $\mathrm{Gee}^{16}$ one at 6 weeks of age. After the eighteenth month a first attack is rare, but there may be recur-

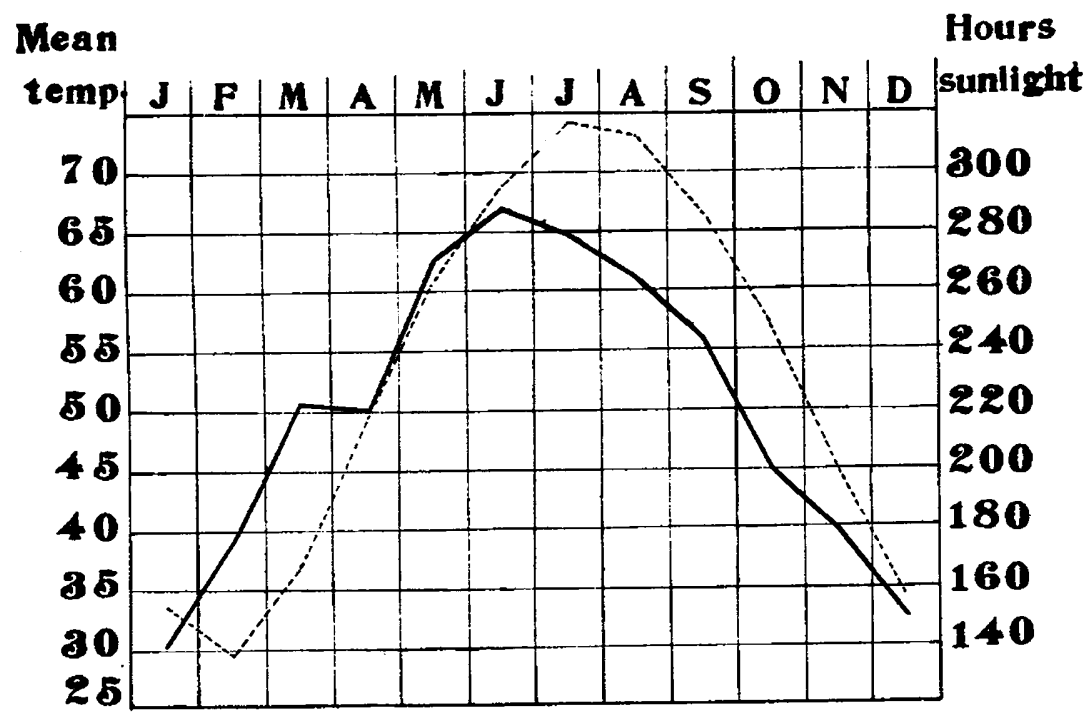

Fig. 2.-New York City, 1911-1917; — number of hours of sunlight; - - - - mean temperature.

rences at that time. In some of the late cases, the original attack may have been overlooked. My oldest patient was 4 years of age. Henoch reported a case of 3 years, Still one of 4 years, and Mowat ${ }^{17}$ one of 5 years. It is pretty well established that head shaking is a developmental disease, and that it occurs in certain predisposed infants at a time when the associated movements of the head and eyes are being perfected.

Family history.-In very few of my series, was there a distinct neuropathic family history. In 2 instances the parents were cousins. In 4 cases the mother was extremely nervous, in 3 markedly anemic;

15. Schoenberg: Norsk Mag. f. Lægevidensk., 1891, p. 467.

16. Gee: St. Barthol. Hosp. Rep., 1886, 22, 96.

17. Mowat: Lancet, London, 1906, 2, 397. 
1 had frequent attacks of migraine; 1 had hysteria. In 5 families one or more of the other children had convulsions; in 1 family one child had epilepsy, and in another family a child died of meningitis. In one instance the condition occurred in twins, and in another family two children were affected. Henoch and Reyher also observed the disease in twins; and Thomson and Hadden have reported instances of more than one case in a family. Three of my cases occurred in mongolian imbeciles. Unlike the latter disease, head shaking does not attack more frequently the first or last child, and it is not more common in families in which there are a large number of children.

Previous history.-In three of my series, the labor was difficult and the delivery instrumental; one was a "twilight" baby, and one was prematurely born. None of these factors seem to play a part in the causation of head shaking.

Feeding.-At the onset of the disease, thirty-five of my patients were breast fed, eighteen artificially fed, and eleven were on mixed feeding, so that the character of feeding has no direct relation to the disease. As one would expect, the rachitic manifestations when present, were more marked in the artificially fed infants, so that to a certain extent such infants were somewhat more predisposed to head shaking.

Previous disease.-Illness, by lowering the vitality, apparently is an etiologic factor in those infants who are already predisposed. Five of my cases followed an attack of bronchitis, 3 followed pneumonia, 6 patients had digestive disturbances, 2 measles, and 1 each nasopharyngitis and otitis. Intercurrent disease tends to increase the head and eye movements.

Teething.-It is to be expected that this condition, which plays such an important etiologic rôle in the minds of mothers, should also be held responsible for head shaking. It would not be surprising if the nystagmus were ascribed to the eruption of the "eye" teeth. Ebert, Henoch, and Still, believe that the eruption of teeth often plays an important part as a source of peripheral irritation. In exceptional cases this may be so, but I have not been able to convince myself that the rôle is an important one. In 18 of my cases the onset of the disease antedated the eruption of teeth. Ebert, who first described the condition, writing in 1850, says, "It is well known that febrile and spastic conditions which are related to the eruption of teeth may antedate the actual appearance of the teeth." If we accept this statement, then anything is possible. I recently saw an infant in whom the eruption of two incisors occurred on the day on which a measles eruption appeared. To the lay mind it seems like cause and effect. In my patients teeth appeared during the course of the disease, but 
I never noticed an exacerbation of the symptoms at that time. Fatigue does tend to increase the symptoms, so that it is possible that a fretful child that is teething may sleep less, and in that way the head movements might become more distinct. Other sources of peripheral irritation, worms, otitis, etc., have been mentioned as causes, but the evidence is not conclusive.

Trauma. Fall.--In a small percentage of cases this may reasonably be considered an exciting cause in a predisposed child ; but it must be remembered that a large number of infants fall and very few show any permanent injury. Only when the head shaking begins shortly after the fall can a relation be claimed; and it is also possible that the fall is a symptom of an already existing coordination neurosis rather than its cause. In six of my series there was a definite history of a fall just preceding the onset of the disease. In one of Hadden's patients two relapses occurred following falls on the head. Peterson ${ }^{8}$ says: "Perhaps a concussion of some kind may be found in most of the cases to be the determining factor-a concussion setting up in the centers of the spinal accessory and at times in those of the oculomotor nerves an arrhythmic discharge."

Hygienic conditions, social position, location of rooms.-The hygienic conditions and social position of the family play an important part. Many authors say that the disease does not occur among the well-to-do. This is not absolutely correct, as I have had two cases in families in comfortable circumstances, and Still mentions having seen three such cases. It is rare, however, among this class compared with the frequency with which rickets, laryngismus stridulus, tetany and convulsions occur in them. In large cities, head shaking is more common among those who live in the poorer tenement districts. In my series 11 families lived in the basement, 20 on the first floor, 9 on the second floor, 12 on the third floor, 7 on the fourth floor, and 5 on the fifth or top floor. It will be noted that one half of the families lived in the basement or on the first floor; those living in the basement were not only the poorest, but their rooms were dark and ill ventilated, and the intelligence of the mothers was lower than the average.

Dark rooms.-In 55 of the cases of my series the character of the rooms could be accurately ascertained. I visited nearly all of them myself. It is important to investigate oneself and to determine the exact conditions during the months preceding the onset of the disease. The crib may be placed in a dark corner of a room, not otherwise very dark; the shades may be drawn down a large part of the day so as to darken the room and favor sleep, or the crib may be curtained in order to prevent the light from shining in the infant's eyes. In 40 of my series, the infant was more or less in the dark, and in a 
large number of these cases it was necessary to use artificial light in the afternoon during the winter months. In the remaining 15 the room and the spot where the infant lay were fairly light, and in a few of these the room was bright even during the winter months. In several cases, although there was a light room, the infant was kept most of the time in the kitchen, a dark room, so that the mother could watch it while cooking; in several others it was impossible for the mother to take the baby out on account of sickness or the large number of other small children that required attention. On the other hand, in a few cases the mother definitely said that the baby was taken out regularly. It must be remembered that in certain crowded sections of the city a large number of people live in dark rooms, so that only a small portion, probably not more than 1 in 100 infants living in such rooms, contract the disease. Here again we must assume an individual predisposition. The same has been noted in so-called miner's nystagmus; only 3.5 to 4 per cent. of all coal miners working under exactly the same conditions are affected. There can be little doubt that the dark room is an important factor in a large number of the cases of head shaking. During the last eleven years $I$ have seen the same class of patients at the Lebanon Hospital outpatient department in the Borough of the Bronx as I saw during 1899-1902 at the Good Samaritan Dispensary on the Lower East Side of New York. Making due allowance for the difference in the number of patients, the disease was more common in the latter section, principally, I believe, because in the Borough of the Bronx the majority live in rooms which are better lighted and better ventilated. A series of 4 cases of head shaking reported by Rietschel ${ }^{18}$ from Finkelstein's service is interesting. On account of the suspicion of communicable disease these 4 infants were transferred from the well lighted ward of the infant asylum to the dark room of a barracks. Shortly after, they developed head shaking. One of the infants was returned to the well lighted and well ventilated ward of the asylum and the head movements soon disappeared. Raudnitz was able to produce experimentally a similar head shaking with nystagmus in puppies by placing them in a dark cage at or very shortly after birth. In from six to eight weeks they developed nystagmus, and after three or four months, shaking of the head. If they were placed in a darkened cage after they were 2 months old, these symptoms did not develop. Here again we note, that the causative factors act only at a certain stage in the development of the nervous mechanism which controls the associated movements of the head and eyes. As in infants, at first the nystagmus was only seen

18. Rietschel: Charité-Ann., 1906, 30, 152. Rietschel refers to John Thomson of Edinburgh, as an American. We sheuld be very glad to claim him. 
when the animal looked in certain directions or when the head was held, and the head movements ceased when the eyes were bandaged. If the animals were placed in the open a few days after the nystagmus first showed itself, it disappeared in from one to two weeks, and if they were returned to the dark cage, the nystagmus reappeared in from two to seven days. If the animal was kept in the dark, however, so that the nystagmus persisted for several months, it required as much as nine months' exposure to daylight to cause the nystagmus to disappear. The examination of the fundus, the vision, and the microscopic examination of the brain and retina of the affected aninals showed no pathologic changes. It is worth noting that in Raudnitz' experimental work on animals the cage was dark and apparently there was no artificial light to which the eyes of these young animals was attracted. In explaining the causation of the condition in infants he laid stress on the straining of the eyes in looking at an artificial light some distance above the level of the head. Raudnitz believes that the nystagmus associated with the head shaking in infants is analogous to that observed in coal miners. ${ }^{19}$ Although there are some points of analogy, there are some objections to this theory. The nystagmus of coal miners seems to be due to the strained position of the head, eyes, and body of the men, working in a place which is imperfectly lighted. The darkness alone is not sufficient, for this form cf nystagmus occurs only in coal miners. The strained position of the head and eyes alone is not sufficient, for it does not occur in ceiling painters, and in others who have to look more or less constantly upward. A large percentage of the miners affected have errors of vision, while the infants with head shaking associated with nystagmus have no such error. The nystagmus of miners is usually bilateral and conjugate; that of the infants is usually unilateral, or is much more marked in one eye, and is frequently not conjugate. In miners head movements are uncommon and are only present in severe cases; in infants head movements are the rule. In miners the head movements do not cease when the eyes are bandaged as they do in the infantile form.

Rickets.-Kassowitz, ${ }^{20}$ Hochsinger ${ }^{21}$ and Stamm $^{22}$ consider the head shaking of infants a rachitic manifestation. In my series, 45 , or 70 per cent., of the patients showed some manifestations of this discase. This is about twice as frequent as in other infants brought for treatment. Thomson's figures are 94.2 per cent. rickets in the affected infants, 46.9 in other infants. Of course the percentage of rickets

19. Nieden: Nystagmus der Bergleute. Wiesbaden, 1894.

20. Kassowitz: Vorles. u. Kinderk. im alter d. Zahnung, Vienna, 1892, p. 165.

21. Hochsinger: Verhandl. d. Gesellsch. f. Kinderh., 1897, 14, 238.

22. Stamm: Arch. f. Kinderh., 1902, 32, 259. 
will vary according to the clientêle. For example, in New York City, rickets is much more common in negro children, so that it is not surprising that every one of my 10 cases of head shaking in negro children showed distinct rachitic changes. ${ }^{23}$ However, in 19 of my cases rickets was not present, so that it cannot be an indispensable factor. Several other points indicated by Thomson are of interest. In head shaking, antirachitic treatment is not followed by the rapid improvement which we are accustomed to see in rickets. This has been my own experience and is contrary to that of Stamm, who noted distinct improvement in the head shaking in a few weeks. Cases of head shaking are rarely associated with laryngismus stridulus, facial irritability, tetany or convulsions. In my series, although many had marked rachitic manifestations, only 3 had laryngismus stridulus and facial irritability, and in Thomson's 35 cases only 2 had laryngismus stridulus and facial irritability. There does not seem to be a distinct relation between the frequency of laryngismus stridulus and head shaking in a given locality. In Vienna, Kassowitz in six years saw 370 cases of laryngismus stridulus, that is on the average 61 cases a year; in Edinburgh, Thomson in three years saw only 61 cases, that is, 20 a year. $O_{1}$ the other hand, Kassowitz in eight years saw only 9 cases of head shaking; that is, about one a year, while Thomson saw 35 cases in eleven years; that is, 3 a year. If these conditions were due, as Kassowitz supposes, to the increased vascularity of the bones of the skull and the neighboring tissues, then we should expect that head shaking would be frequently present in rachitic infants with craniotabes; however, such is not the case. Rietschel tested the electrical reactions in 4 cases of head shaking, and 3 of the 4 gave normal reactions. While head shaking is rare in well-to-do families, rickets, laryngismus stridulus, tetany, and convulsions are not uncommon. As is well known, rickets involves not only the bones, muscles and ligaments, but the central nervous system as well, so that it is not surprising that a rachitic infant should be somewhat more predisposed to the development of a functional neurosis.

Pathogenesis,-Notwithstanding the great amount of investigation on this subject, the exact explanation of the disturbance of the nervous mechanism which results in the head and eye movements is still something of a puzzle. The solution requires the combined investigation of the pediatrist, neurologist, and ophthalmologist. Thomson says :

The nervous mechanism whose function is at fault is evidently that which includes the semicircular canals in its circuit, and which regulates the coordination of the movements of the eyes with those of the head. Dr. Alex Bruce tells me that the nucleus of Deiters (one of the end nuclei of the vestibular

23. Herrman: Arch. Pediat., 1910, 27, 370. 
nerve, lying at the lateral angle of the fourth ventricle) is in all probability the seat of the disturbance. He infers this from its connection with the oculomotor nuclei and with the anterior cornua of the cord.

Henoch had about the same in mind when he wrote:

The frequent combination of head shaking with nystagmus is interesting, as it indicates that the nuclei of the spinal accessory and the upper spinal nerves which supply the affected muscles of the head and neck, are in close relation to those of the eye muscles.

The most satisfactory explanation of the pathogenesis of this condition is that originally suggested by Hadden and later modified and amplified by Mills ${ }^{24}$ and Aldrich. Mills says:

Hadden believes that the symptoms point to an instability of the motor centers above the nuclei in the spinal cord and fourth ventricle, and he would therefore attribute the disorder to a functional or other disturbance of the cerebral cortex. The child has acquired certain voluntary or purposive movements of the head and eyeballs, but these have not as yet become thoroughly organized and fixed in the psychomotor areas of the brain, hence a dissolution takes place because of the instability of the strained cortical centers to stand the work to which they have been too early subjected.

\section{Aldrich amplifies this as follows:}

The writer in considering the pathology of these cases accepts as a fact the obvious relation of the head and eye movements, hence we have to consider an automatic head and eye movement in a child of unstable nerve development, and at an age in which the associations of those necessary movements are being educated and fixed in the psychomotor areas of the brain. Anyone that has observed the head and eye movements of the infant cannot have failed to mark the incoordinated attempts at associated movements of the head and eyes. The fibrous connection between the visual areas of the cerebral cortex and the fovea centralis that is necessary to perfect vision does not fully develop until after birth, and only gradually becomes medullated and fit for function. After this process is completed, which takes place only when the cortical cell has attained a degree of maturity that provides ample nutrition for its axis cylinder, then the structural and physiologic integrity of the central neuron is complete. During this time the same process of development in the peripheral neuron is going on with even greater rapidity, and we have the beginning of one of the most wonderful and mysterious processes of the nervous system-the communication between the central and peripheral neuron. . . Binocular adjustment, judgment of fixed objects, spatial relations, including station, are acquired by the child as the medullation progresses. If this progress of medullary development of the nerve supply of the eyes is either interfered with by disturbance of nerve nutrition or rendered functionally imperfect through early acquired opacity of the refracting media, or by congenital absence of a place in the retina that has more acute and perfect vision than elsewhere (fovea centralis), or a congenital defect in the receptive center in the cortex, or an exhaustion of any of that delicate apparatus, then we are liable to get a rapid to and fro movement of the eyes-nystagmus.

Symptoms. Movements of the head.-The movement of the head is usually the first manifestation noticed by the mother, but in a

24. Mills: Am. Textbook Dis. Child., Ed. 2, 1894, p. 712. 
certain number it may be preceded by a peculiar "cocking" of the head to one side. In some the nystagmus may precede the head movements but may not be noticed because it is present only when the child looks in certain directions, or when the head is held. The muscles chiefly affected are the sternocleidomastoid, the trapezius and the rectus capitis. The movements are regular and rhythmical and from 60 to 100 a minute. Usually they are not continuous, but come on at longer or shorter intervals. The direction is rarely purely horizontal, vertical or rotary, but when primarily horizontal, slightly upward to one side and downward to the other, the excursions often being greater to one side. If primarily vertical, it is rarely a pure nod forward and backward. The movement may be a combination of the horizontal and vertical, and they may be in different directions at different times. In my series the movements were primarily horizontal in 44 , vertical in 12 , rotary in 4 , and horizontal or vertical at different times in 4 . The movements are often more distinct when the child is angry or fatigued, and during an attack of some intercurrent disease. They cease when the child is lying down and in sleep. There is, however, an occasional exception to this rule; for example, in one of my cases, in which the movements were unusually frequent and well marked, they continued when the child was lying down, and Amberg ${ }^{25}$ also mentions a case in which the movements continued during sleep. It was first noticed by Caillé, and later by Raudnitz, that the movements of the head ceased when the eyes were bandaged. It is not possible ic test this in all patients, because some object so strongly that the movements of the head due to anger prevent the drawing of definite conclusions; but in 14 of my cases, I was able to corroborate this statement. The movements of the head are best seen when the infant is gazing in the distance and is not interested in any particular object. If an object is brought within a short distance, so that it is definitely fixed, the movements of the head cease.

Movements of other parts of the body.-I have not observed movements of the extremities, such as described by Thomson, Still, and others, or of the trunk, as reported by Hadden. Ausch ${ }^{26}$ noticed in one of his cases movements of the hands, as if the child was vexed. I have frequently seen such movements in infants who were entirely free from head shaking.

The peculiar position of the head.-(Fig. 3).-About one-half ot these patients have a peculiar way of "cocking" the head to one side and looking out of the corners of the eyes. This may precede the head movements and may persist after these movements have ceased. In

25. Amberg: Arch. Pediat., 1901, 18, 831.

26. Ausch: Arch. f. Kinderh., 1900, 28, 161. 
75 per cent. of the infants in whom this "cocking" was present the head was inclined to the left. This is noteworthy in connection with the fact that in sixteen of the twenty-three cases in which the nystagmus was unilateral, the left eye was affected. Some of the patients have a habit of looking down with a coy expression; others throw the head back and look out of the partially closed lids.

Movements of the eyes.-The nystagmus may appear before, simultaneously with or after the head movements. It may persist after the head shaking has ceased. In 35 of my cases the nystagmus was bilateral, in 23 unilateral. Of the latter, 16 affected the left eye, 7 the right eye. Even when the nystagmus was bilateral, it was trequently more marked in one eye. In 6 cases the nystagmus was not seen when the patients were examined in the ordinary way, but it is known that in some cases the nystagmus is so slight that it can only be detected by an ophthalmoscopic examination. The direction of the

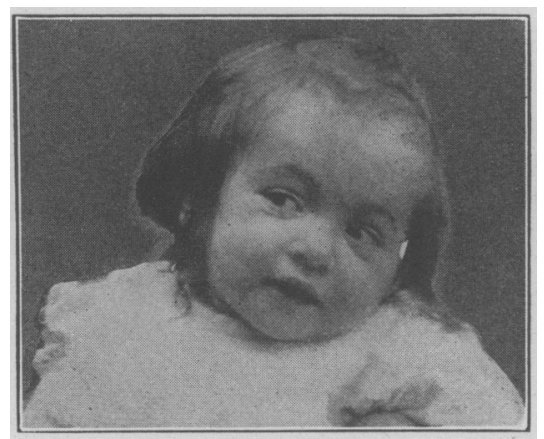

Fig. 3.-Peculiar cocking of the head seen in infants affected with head shaking with nystagmus.

nystagmus is often not purely horizontal, vertical or rotary; it niay be different in the two eyes, or when the patient looks in different directions. In the 58 cases in my series in which nystagmus was present, it was primarily horizontal in 36 , vertical in 6 , and rotary in 15 ; in the remaining case it was impossible to determine the direction. The movements of the eye are much more rapid than those of the head, about 200 to 300 a minute. The nystagmus is increased by holding the head, and is more distinct when the child looks in certain directions, usually when it looks upward and to the right, when the right eye is affected, and upward and to the left, when the left eye is affected. It is also more distinct when the child fixes an object at a short distance, and when the eyes are converged. It is not present during sleep, as I was able to determine in several infants that I examined. When the nystagmus is bilateral it is not necessarily conjugate. According to Thomson, ${ }^{7}$ it differs from other forms in that 
the pupils alternately approach and recede. Spicer ${ }^{2 \pi}$ was not able to verify this in all of his cases. Thomson also says that in rotary nystagmus the center of the pupil does not describe a circle, but an ellipse or an irregular figure. The movements of the head are not simply compensatory to those of the eyes, for the rate is different, and the two are not necessarily in the same direction; for example, the movements of the head may be vertical, while those of the eyes are horizontal. The nystagmus may persist after the head movements have ceased, and it may recur without the appearance of head movements. In exceptional cases the nystagmus may be the only manifestation. Such cases may be regarded as atypical or incomplete. In 4 of my series, convergent strabismus was present; in 3 there was hippus; 3 had associated movements of the upper lids, "nictitation;" and in 2 there was some sensitiveness to light; 12 of my patients were examined by ophthalmologists, and none of these showed any changes in the fundus, defects of vision or opacities in the media. Similar examinations reported by other authors were also negative, except that in two of Hadden's cases the fundus was light colored, and in one a slight crescent of atrophy was present around the left disk. In a few of my patients, I instilled homatropin in order to paralyze accommodation. The nystagmus was diminished, but the head movements continued. This is what one would expect, for as previously mentioned, the head movements cease when an object is distinctly seen and fixed; by paralyzing accommodation this becomes impossible. As nystagmus is sometimes associated with disturbances in the semicircular canals, Raudnitz had the ears examined in several cases. None showed any lesions, and syringing of the ears had no especial effect on the nystagmus.

Associated conditions. - In my series, 6 patients were anemic, 5 had an enlarged spleen, 2 tuberculous lesions, 2 papular urticaria, 2 eczema, 3 a geographical tongue, 1 blepharitis ciliaris. One child had attacks of apnea. Hadden reports cases with attacks of unconsciousness, partial or complete, and convulsions. Such cases are rare, and the more severe probably represent cases of so-called epilepsia nutans.

Duration.--The condition seldom lasts less than 2, or more than 12 months. In my series, the duration of 50 cases could be determined. In 6 it was 3 months; in 6 it was 4 months; in 12 it was 5 months; in 6 it was 6 months; in 4 it was 7 months; in 4 it was 8 months; in 2 it was 9 months; in 4 it was 10 months; in 6 it was 12 months. In 3 there was a recurrence during the following winter, 2 in January and 1 in February. In exceptional cases, however, the disease may last for more than one year. Spicer mentions a case in

27. Spicer: Brit. Med. Jour., 1901, 1, 1120. 
which it was present at $4 \mathrm{~T} / 2$ years of age; and another in which the nystagmus persisted at 13 years of age.

Subsequent history.-I have been able to follow 15 of my cases for a period of from two to ten years. Of these, 8 had no subsequent disease that had any relation to the head shaking. Of the remaining 7,2 had enuresis, one of these until she was 6 years of age; 1 had convulsions; 1 pavor nocturnus; 1 a facial tic; 1 was extremely sensitive and also anemic; and 1 was a very restless sleeper and had grinding of the teeth. With the exception of the 3 cases in mongolian imbeciles, all the children showed a normal average mental development. I recently saw a girl of 13 years with a mild type of exophthalmic goiter (Graves' disease) who had had head shaking in infancy. In none of the 5 children who were followed to the eighth year did chorea develop. This is of some interest, as several authors have thought that there was a possible relation between these two diseases.

Diagnosis.-The principal features of this condition are so characteristic that the correct diagnosis is seldom difficult. Some of the earlier authors confused it with eclampsia or epilepsia nutans, which is really an epileptic equivalent. This disease occurs in attacks, and is associated with partial or complete unconsciousness. There is no nystagmus. In head shaking there are no sudden attacks, the movements are more or less continuous, and consciousness is not lost. The movements in head shaking are entirely different from those of a tic or habit spasm. They are smooth, regular, and rhythmical, not jerky. Tics do not occur at such an early age, and they are not associated with nystagmus. The rocking movements of the trunk and head, frequently seen in infants and young children, have only a remote resemblance to head shaking. The movements are voluntary, and even when they are not a manifestation of masturbation, seem to give the patients a certain amount of pleasure or satisfaction. Nystagmus is absent. Head shaking has occasionally been confused with the nocturnal movements of the head, Jactatio capitis nosturnia, which is sometimes seen in older children. These movements differ from the head shaking of infants in that they occur during sleep, or at least in a subconscious state, and are not associated with nystagmus. Head rolling, like head shaking, is seen in rachitic infants, but it is only present when the child is lying down; it is a voluntary act, and it is not associated with nystagmus. There is a rare form of congenital head shaking with nystagmus which is due to pathologic changes in certain areas of the brain. This condition as well as a number of other diseases of the central nervous system, associated with head movements or nystagmus, can easily be differentiated from the benign head shaking of infants, by the fact that the disease is progressive and 
fersists throughout life. In all these conditions when nystagmus is present it is bilateral and conjugate.

Prognosis.--Head shaking with nystagmus in infants is a benign disease; all patients recover. The mothers may be assured that this disease will not interfere with the general health, or with the future mental and physical development of the child. The disease usually begins in the winter months and disappears during the following summer. Occasionally there is a recurrence of symptoms the following winter, but this also is of short duration. A few of the patients show a neuropathic tendency in later childhood.

Treatment. - The general condition, the hygienic surroundings, should be improved if possible. The room should be light, and the patient should be kept in the open air as much as possible. In several of my cases the mother noticed that there was a rapid improvement when the child was taken to the country. If there are any sources of peripheral irritation, these should be removed; if there are digestive disturbances, the diet should be regulated. Those infants that present rachitic manifestations should receive phosphorus and cod liver oil. In most cases this treatment is sufficient. I have not seen any marked improvement following the administration of bromids, belladonna or arsenic.

250 West Eighty-Eighth Street.

In addition to the numbered references the following authors have also published cases :

Buzzard: Lancet, London, $1886,1,834$.

Mackenzie: Lancet, London, 1886, 1, 833.

Norrie: Lancet, London, 1890, 2, 1264; Ophth. Review, 1888, p. 355.

Dickson: Lancet, London, 1895, 2, 845.

McGillivray: Ophth. Review, 1895, 14, 252.

Lange: Verhandl. d. Gesellsch. f. Kinderh., 1897, 14, 231.

Meyer: Deutsch. med. Wchnschr., 1897, 23, 849.

Hirsch: New York Med. News, 1898, 72, 538.

Hand: Arch. Pediat., 1898, 15, 694.

Jopson: Arch. Pediat., 1901, 18, 285.

Eshner: Arch. Pediat., 1901, 18, 598.

Foellinger: Inaug. Dissert., Leipsig, 1903.

Swoboda: Gesellsch. Aerzte Wien., Feb. 20, 1903.

Jacquet: Thèse de Paris, 1903.

Wholey: Jour. Am. Med. Assn., 1907, 48, 475.

Gibson: Brit. Med. Jour., 1909, 2, 314.

Strauss: München. med. Wchnschr., 1910, 77, 531.

Babonneix: Arch. de méd. d. enf., 1910, 13, 159.

Gismondi : Pediatria, 1912, p. 449. 